\title{
Psychological distress prior to surgery is related to symptom burden and health status in lung cancer survivors
}

\author{
Marta Linares-Moya ${ }^{1}$ · Janet Rodríguez-Torres ${ }^{1}$ - Alejandro Heredia-Ciuró ${ }^{1} \cdot$ María Granados-Santiago ${ }^{1}$. \\ Laura López-López ${ }^{1} \cdot$ Florencio Quero-Valenzuela $^{2} \cdot$ Marie Carmen Valenza $^{1}$
}

Received: 10 May 2021 / Accepted: 31 August 2021 / Published online: 20 September 2021

(c) The Author(s) 2022, corrected publication 2022

\begin{abstract}
Purpose Patients with lung cancer experience a variety of distressing symptoms which could adversely affect quality of life. The aim of this study was to determine whether psychological distress prior to surgery is associated to health status and symptom burden in lung cancer survivors.

Methods A longitudinal observational study with 1-year follow-up was carried out. Health status was measured by the WHO Disability Assessment Scale (WHO-DAS 2.0), the Euroqol-5 dimensions (EQ-5D) and the Pittsburgh Sleep Quality Index (PSQI). Symptoms severity included dyspnoea (Multidimensional Profile of Dyspnoea); pain (Brief Pain Inventory); fatigue (Fatigue Severity Scale); and cough (Leicester Cough Questionnaire).

Results One hundred seventy-four lung cancer patients were included. Patients in the group with psychological distress presented a worse self-perceived health status, functionality and sleep quality. The group with psychological distress also presented higher dyspnoea, fatigue and pain.

Conclusion Patients with psychological distress prior surgery present with a greater symptom burden and a poorer selfperceived health status, lower functionality and sleep quality, than patients without distress 1 year after the lung resection.
\end{abstract}

Keywords Lung cancer $\cdot$ Health status $\cdot$ Survivors $\cdot$ Symptoms

\section{Introduction}

Lung cancer (LC) is the leading cause of cancer-related mortality worldwide [1], accounting for $27 \%$ of cancer deaths in 2014 [2]. Improvements in the diagnosis and treatment of LC have resulted in increased opportunities for long-term survival $[3,4]$. Curative lung resection is the preferred treatment for early-stage lung cancer, significantly improving 5-year survival rates in this population [5]. This has led to a growing interest in addressing issues faced by these longterm survivors [6], identifying the physical and psychosocial factors affecting their well-being [7].

LC patients present various symptoms, such as pain, coughing, fatigue and shortness of breath in the early stages

Marie Carmen Valenza

cvalenza@ugr.es

1 Department of Physical Therapy, Faculty of Health Sciences, University of Granada, Av. De la Ilustración, 60, 18016 Granada, Spain

2 Hospital Virgen de Las Nieves, Granada, Spain after surgery or even a long time after surgery [8-10]. Moreover, patients with lung cancer experience a variety of distressing symptoms, many of which begin before diagnosis and continue throughout the course of the disease and its treatments, adversely affecting functional status and quality of life (QOL) [11-13].

Psychological distress has been defined by the National Comprehensive Cancer Network as "an unpleasant experience of an emotional, psychological, social, or spiritual nature that interferes with the ability to cope with cancer treatment" [14]. It includes a wide continuum of psychological feelings relating to worry, anxiety, depression, fear and sadness and extends on a continuum from common normal feelings of vulnerability to problems that are disabling, such as true depression $[15,16]$.

Psychological distress prevalence rates in patients with cancer range from 22 to $58 \%$ [17, 18], with a higher prevalence among lung cancer patients when compared to patients with other cancers $[19,20]$. Higher psychosocial distress can result from a late diagnosis, smoking, multiple symptoms, financial problems and health-related stigma [21-24], and 
could exacerbate disease-related symptoms contributing to poorer QOL outcomes well into survivorship [25]. This is consistent with theories such as the somatic perception hypothesis [26, 27] and somatosensory amplification [28], which posit that psychological factors, such as negative effects, can influence the perception and appraisal of somatic sensations or symptoms through their effects on higher cognitive processing patterns.

The clinical importance of assessing and treating psychological distress and mood disorder has received much attention from patient advocacy groups and health care providers, including consideration of distress as the sixth vital sign in cancer care [29]. However, despite being one of the most frequent cancers worldwide, little research has been done concerning the influence of psychological distress on symptom burden and health status in lung cancer survivors in the long term [30]. So, this study aimed to determine whether psychological distress prior to surgery is associated with health status and symptom burden in lung cancer survivors. We hypothesized that psychological distress before surgery could be related to a worse recovery in lung cancer survivors.

\section{Methods}

A longitudinal observational study with a 1-year follow-up was carried out. We recruited patients above 18 years of age diagnosed with lung cancer and undergoing pulmonary resection, from the Thoracic Surgery Service of the "Virgen de las Nieves" Hospital Complex in Granada (Spain) between October 2018 and January 2020. All patients were informed about the purpose of the study and signed an informed consent form prior to their inclusion. Patients were excluded if they had one of these conditions: cognitive impairment or mental instability, physical disabilities that prevented their evaluation, inability to communicate, contraindication to physical exercise and presence of other respiratory pathologies. They were also excluded if they have suffered from any important pathology in the last year which could affect the study results. Ethical approval for this study was obtained from the Biomedical Research Ethics Committee of Granada.

Data collection was performed at admission and 1 year after hospitalization, by the same researchers, who had been previously trained. The evaluation was performed in the "Virgen de las Nieves Hospital Complex", at admission, and in the Health Sciences Faculty of the University of Granada, 1 year after hospitalization.

Patients' medical history was verified to confirm that they met the inclusion criteria. Data collected from the medical history included anthropometric data, comorbidities and lung resection characteristics, including type and duration of the surgery. Comorbidities were assessed by the Charlson index, one of the most widely used scoring systems for assessing comorbidities, and it has been validated in several disorders [31].

\section{Group assignment}

Patients were divided into two groups based on the presence of psychological distress at hospital admission, assessed by the Hospital Anxiety and Depression Scale (HADS). The HADS is a questionnaire that has been previously used as a screening tool for psychological distress [32]. The questionnaire consists of 14 items, scored on a scale of $0-3$. It is divided in turn into two subscales, one for anxiety (consisting of 7 items) and another for depression (consisting of 7 items), the higher score in each subscale greater anxiety or depression, respectively [33]. The cut-off point used was 11, based on previous studies with cancer patients [32].

\section{Outcome measures}

Health status and symptoms severity were included as main outcomes. Health status was measured by the WHO Disability Assessment Scale (WHO-DAS 2.0), the Euroqol-5 dimensions (EQ-5D) and the Pittsburgh Sleep Quality Index (PSQI). Symptoms severity included dyspnoea, assessed by the Multidimensional Profile of Dyspnoea (MDP); pain, evaluated by the Brief Pain Inventory (BPI); fatigue, assessed by the Fatigue Severity Scale; and cough, measured with the Leicester Cough Questionnaire (LCQ).

WHO-DAS 2.0 is a generic tool for measuring health and disability in clinical practice, measuring changes in performance and their levels of difficulty in performing their activities. The scale consists of 36 items, divided into 6 domains, which are scored from 1 (slight) to 5 (extreme/unable to do so). The minimum score is 36 and the maximum is 180 . This means that the greater the number, the greater the disability [34]. This test has high reliability and good validity [35, 36].

EQ-5D is a validated tool to measure self-perceived health status. It has been validated in Spanish [37]. It is divided into two sections, the first of which contains five items about mobility, self-care, usual activities, pain/discomfort and anxiety/depression. These questions were scored between 1 and 3, where 1 represents "no problems" and 3 refers to "extreme problems". The second section is a VAS that measures patients' self-evaluated health status from 0 to 100 (0 represents "the worst imaginable health" and 100 indicates "the best imaginable health").

The PSQI is a self-rated questionnaire that assesses sleep quality and disturbances over a 1-month time interval [38], with strong reliability and validity [39]. It includes seven components: subjective sleep quality, sleep latency, sleep 
duration, habitual sleep efficiency, sleep disturbances, use of sleeping medication and daytime dysfunction.

The symptom severity assessment included dyspnoea, pain, fatigue and cough.

Dyspnoea was assessed with MDP that punctuates the general discomfort of the breath and the sensory and affective decreases of the dyspnoea [40, 41]. It also evaluates the dyspnoea at a specific moment or activity and it is valid and reliable for measuring these sensations in patients with respiratory problems [40]. It consists of 11 items, which the higher the score, the greater the dyspnoea perceived by the patient.

The pain was assessed with BPI, a questionnaire developed by Daut in 1983 and validated in Spanish by Badia et al. in cancer patients in 2002 [42]. BPI is a multidimensional pain assessment tool that provides information on the intensity of pain and its interference in patients' daily activities. The version used includes 9 questions, the higher the score, the greater pain perceived by the patient [42], which has shown excellent reliability and validity in terms of psychometric evidence [43].

Fatigue was assessed with FSS, a self-administered questionnaire with 9 elements that assess the severity of fatigue in different situations [44]. The rating of each element varies from 1 to 7 , where 1 indicates a strong disagreement and 7 strongly agree, and the final rating represents the average value of the 9 elements. The maximum score is the sum of all items, which would be 63 , and the minimum 9 . The higher the score, the more fatigue perceived by the patient (Valko PO et al., 2008). This scale showed good reliability and validity in terms of psychometric evidence.

Cough was assessed with LCQ [45], a questionnaire translated and validated into Spanish [46]. It is short and easy to administer, consisting of nineteen items with scores on a Likert scale ranging from 1 to 7 . It is divided into three subscales: physical, psychological and social. The minimum and maximum score are 3 and 21, respectively, where a lower LCQ score means the presence of a higher cough.

\section{Statistical analysis}

A priori power analysis with $G *$ Power 3.1.9.2 software was performed based on a pilot study (unpublished) of fifteen subjects (effect size of 0.50) obtaining a statistical power of 95\% and a sample size of 176 ( 88 per group). However, 97 participants per group were recruited to allow for a dropout rate of $10 \%$.

Statistical Package SPSS version 20.0 (International Business Machines, Armonk, NY) was used to analyse the data obtained. Prior to statistical analysis, the Kolmogorov-Smirnov test was performed to assess the normality of the variables. Descriptive statistics (i.e. mean \pm standard deviation) were carried out to describe sample baseline characteristics. Between-group comparison was performed after subjects were grouped by psychological distress, using the Student's $t$ test. Statistical significance was accepted at a $p$ value of 0.05 .

\section{Results}

Of 198 potential patients, a final sample size of 174 was selected and divided into two groups depending on the presence of psychological distress. The distribution of patients is shown in Fig. 1. At first, 198 participants were recruited and, after checking the inclusion criteria and signed the informed consent, 24 participants were excluded. The HADS was used to divide the sample into two groups (112 vs 62).

Sociodemographic variables of the sample, duration of the intervention and length of hospital stay are presented in Table 1. The main descriptive variables of both groups are presented in this table.

As we can see in Table 1, significant differences were found in sex, with a higher percentage of women in the group with psychological distress $(p<0.001)$. Nevertheless, no significant differences were found between groups in the other baseline characteristics such as age $(p=0.095)$, BMI $(p=0.732)$, comorbidities $(p=0.896)$ or MNA $(p=0.667)$. Length of hospital stay and duration of intervention were also similar in both groups; however, the group with psychological distress had a longer hospital stay and intervention.

The differences between preoperative and postoperative health status values, 1 year after hospitalization, are shown in Table 2. In this table, WHO-DAS 2.0, PSQI and ED-5D are reported, compared by group.

Concerning to the self-perceived health status of the patients, 1 year after hospitalization, the group who presented psychological distress had worse scores in self-care $(p=0.007)$, pain $(p<0.001)$, anxiety/depression $(p=0.003)$ and VAS $(p=0.002)$.

The patients with psychological distress also presented worse scores in most of the WHO-DAS 2.0 domains (cognition $(p=0.005)$, relations $(p<0.001)$, housework $(p=0.006)$, participation $(p=0.031))$ and the total score $(p=0.002)$.

Regarding the quality of sleep, the group with psychological distress had worse scores in most subscales, being statistically significant in subjective sleep quality $(p=0.022)$ and the total score $(p=0.041)$.

The differences between preoperative and postoperative symptoms, 1 year after hospitalization, are shown in Table 3. This table shows dyspnoea, pain, fatigue and cough differences.

Statistically significant and clinical differences were found between groups in symptoms. The group with psychological distress presented higher dyspnoea $(p<0.001)$, fatigue $(p=0.025)$ and pain $(p=0.043)$ than the group 
Fig. 1 Flow diagram of participants
Table 1 Sociodemographic variables of the sample, duration of the intervention and length of hospital stay

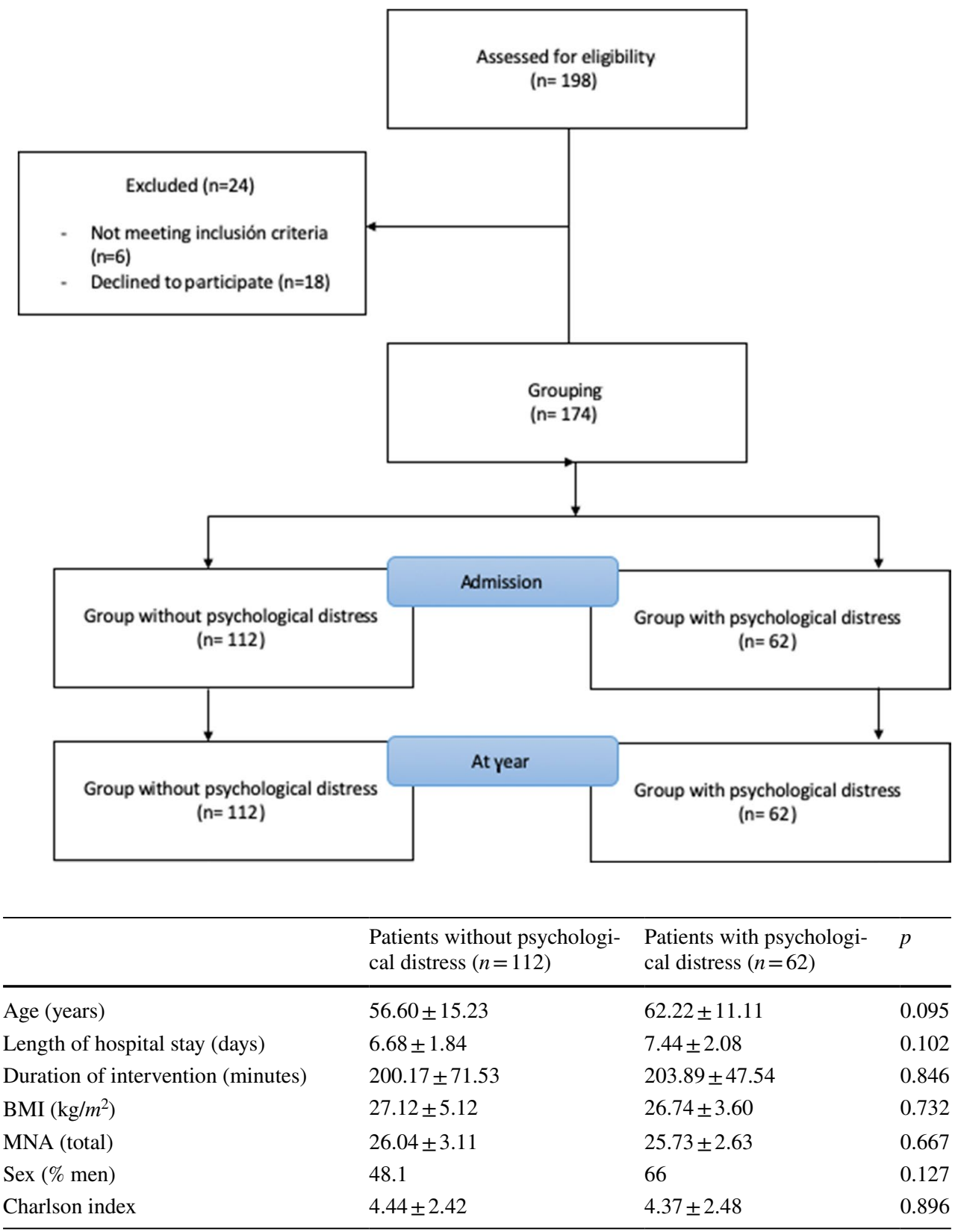

Data are expressed as mean \pm SD or percentage (\%); BMI body mass index; SD standard deviation; FEV1\% forced expiratory volume in the first second in percentage; $* p<0.05, * * p<0.001$ without psychological distress, 1 year after hospitalization. The cough did not present differences between both groups, although the psychological distress group showed worse results.

\section{Discussion}

This study aimed to determine whether psychological distress prior to surgery is associated with health status and symptom burden in lung cancer survivors in the long term.
Our study shows that patients who present psychological distress before lung resection present poorer health status and more symptomatology 1 year after the intervention.

The sample of subjects included in this study was representative of the general population of patients with lung cancer, with a similar age range and surgery characteristics [47-49].

To the best of our knowledge, this is the first attempt to study psychological distress in LC survivors in the long term. Our results report that LC survivors who presented psychological distress prior to surgery present a greater 
Table 2 Differences between preoperative and postoperative health status values, 1 year after hospitalization
Table 3 Differences between preoperative and postoperative symptoms, 1 year after hospitalization
Patients without psychologi- Patients with psychologi- $p$ cal distress $(n=112)$ cal distress $(n=62)$

\begin{tabular}{|c|c|c|c|}
\hline \multicolumn{4}{|l|}{ WHO-DAS 2.0} \\
\hline WHO-DAS 2.0 cognition & $7.55 \pm 1.71$ & $8.81 \pm 4.39$ & $0.005^{*}$ \\
\hline WHO-DAS 2.0 mobility & $5.96 \pm 1.63$ & $6.25 \pm 1.96$ & 0.293 \\
\hline WHO-DAS 2.0 self-care & $4.30 \pm 0.62$ & $4.41 \pm 0.75$ & 0.281 \\
\hline WHO-DAS 2.0 relations & $5.75 \pm 0.99$ & $6.64 \pm 2.26$ & $<0.001 * *$ \\
\hline WHO-DAS 2.0 housework & $5.36 \pm 1.75$ & $6.23 \pm 2.34$ & $0.006^{*}$ \\
\hline $\begin{array}{l}\text { WHO-DAS } 2.0 \text { work and school } \\
\text { activities }\end{array}$ & $3.44 \pm 3.73$ & $3.96 \pm 4.28$ & 0.404 \\
\hline WHO-DAS 2.0 participation & $10.09 \pm 2.58$ & $11.23 \pm 4.32$ & $0.031^{*}$ \\
\hline WHO-DAS 2.0 (total) & $42.42 \pm 7.39$ & $47.58 \pm 13.83$ & $0.002^{*}$ \\
\hline \multicolumn{4}{|l|}{ EQ-5D } \\
\hline EQ-5D VAS & $80.35 \pm 16.98$ & $64.50 \pm 20.57$ & $0.002 *$ \\
\hline EQ-5D mobility & $1.15 \pm 0.36$ & $1.30 \pm 0.47$ & 0.177 \\
\hline EQ-5D self-care & $1.05 \pm 0.22$ & $1.30 \pm 0.47$ & $0.007 *$ \\
\hline EQ-5D usual activities & $1.20 \pm 0.40$ & $1.40 \pm 0.50$ & 0.102 \\
\hline EQ-5D pain & $1.10 \pm 0.30$ & $1.70 \pm 0.47$ & $<0.001 * *$ \\
\hline EQ-5D anxiety/depression & $1.30 \pm 0.46$ & $1.80 \pm 0.76$ & $0.003^{*}$ \\
\hline \multicolumn{4}{|l|}{ Pittsburgh Sleep Quality Index } \\
\hline Sleep disturbances & $0.8 \pm 0.39$ & $1 \pm 0$ & 0.193 \\
\hline Use of sleeping medications & $0.33 \pm 0.78$ & $1.2 \pm 1.55$ & 0.104 \\
\hline Daytime dysfunction & $0.5 \pm 0.80$ & $0.4 \pm 0.52$ & 0.737 \\
\hline Subjective sleep quality & $0 \pm 0$ & $0.6 \pm 0.84$ & $0.022 *$ \\
\hline Sleep latency & $0.5 \pm 0.52$ & $0.4 \pm 0.84$ & 0.737 \\
\hline Sleep duration & $0.5 \pm 0.80$ & $1 \pm 1.33$ & 0.289 \\
\hline Sleep efficiency & $0.33 \pm 0.78$ & $1 \pm 1.33$ & 0.159 \\
\hline Total & $3 \pm 1.47$ & $5.6 \pm 3.8$ & $0.041 *$ \\
\hline
\end{tabular}

Data are expressed as mean \pm SD or percentage (\%); WHO-DAS 2.0 WHO Disability Assessment Scale; $E Q-5 D$ EuroQol-5D Health Questionnaire; EQ-5D VAS EuroQol-5D Visual Analogue Scale Health Questionnaire. $* p<0.05, * * p<0.001$

Patients without psychological Patients with psychological $p$ distress $(n=112) \quad$ distress $(n=62)$

\begin{tabular}{llll}
\hline \multicolumn{2}{l}{ Multidimensional Dyspnoea Profile } & & \\
MDP E total & $3.75 \pm 5.58$ & $17 \pm 13,79$ & $<0.001^{* *}$ \\
MDP SQ & $3.30 \pm 6.48$ & $11.30 \pm 12.43$ & $0.002^{*}$ \\
Brief Pain Inventory & & & $<0.001^{* *}$ \\
Severity score & $1.6 \pm 4.63$ & $10.60 \pm 11.16$ & 0.668 \\
Interference score & $5.4 \pm 13.26$ & $7 \pm 14.17$ & $0.043^{*}$ \\
Total & $7 \pm 17.39$ & $17.6 \pm 21.08$ & $0.025^{*}$ \\
Fatigue Severity Scale & $20.55 \pm 13.98$ & $30.40 \pm 18.69$ & \\
Leicester Cough Questionnaire & & & 0.133 \\
Physical & $6.95 \pm 0.1$ & $6.17 \pm 1.74$ & 0.114 \\
Psychological & $7 \pm 0$ & $6.8 \pm 0.42$ & 1 \\
Social & $7 \pm 0$ & $7 \pm 0$ & 0.129 \\
Total & $20.95 \pm 0.1$ & $19.97 \pm 2.16$ & \\
\hline
\end{tabular}

Data are expressed as mean \pm SD. FSS Fatigue Severity Scale; MDP E Multidimensional Profile of Dyspnoea Affective Scale; MDP SQ Multidimensional Profile of Dyspnoea Sensory Qualities Choice; General $M D P$ Multidimensional Profile of General Dyspnoea; BPI-SP short questionnaire for the evaluation of pain; $L C Q$ Leicester Cough Questionnaire; ${ }^{*} p<0.05, * * p<0.001$ 
symptom burden than patients without distress, with more dyspnoea, pain, fatigue and cough. This is supported by research, linking elevated psychological distress with poor physical, functional and psychosocial outcomes for patients with lung and other cancers [50-53]. Laird et al. [54] analysed a sample of 654 patients with advanced cancer and cachexia, reporting an important relationship between depression and the presence of pain and fatigue. In the same line, Fitzgerald et al. [55] analysed a group of 487 patients with cancer also reporting a significant relationship between depression, fatigue and pain. However, both studies did not focus on a specific type of cancer and they analysed the relationship between variables at a single time. Tishelman et al. [56] also noted that breathing, pain and fatigue were associated with the most distressed subjects in a sample of 400 patients with lung cancer. A recent study [23] also studied the presence of psychological distress in a sample of 2205 newly diagnosed patients with non-small lung cancer (NSLC). Their results showed that emotional problems were related to symptom burden, similar to our results; however, they did not follow the impact of psychological distress in the long term.

A decreased health status, in LC survivors who presented psychological distress prior to surgery, was found in our study, with poor functionality, self-perceived health status and sleep quality. Arrieta et al. [57] analysed a sample of 82 patients with NSLC and found an association between HADS score, quality of life and prognosis, even 6 months after treatment. However, they did not include the symptoms or other factors which could affect the quality of life. González-Saenz de Tejada et al. [58] carried out a similar study in patients with colorectal cancer. They explored the association of psychological status before surgery with changes in quality of life outcomes at 1-year post-intervention. Their results reported that patients with cancer, and absence of psychological distress, before surgery presented better results in quality of life outcomes at 1 year after surgery, similar to our study.

According to our results, PSQI scores have been associated with psychological distress. This corresponds with the literature where the patients' levels of anxiety and depression have been associated with poor sleep quality $[59,60]$. In the same line, Chang et al. [61] reported that the hypothalamic-pituitary-adrenal axis activation caused by increased psychological stress has a pronounced effect on the sleep quality of lung cancer patients. Our study also shows a reduced functionality 1 year after surgery in LC survivors with psychological distress. Similar results were found in the study of Lin et al. [51] where 145 lung cancer patients were analysed, and psychological distress was associated with lower functional status and worse quality of life. Cheville et al. [62] studied a sample of 2405 patients with lung cancer and showed similar results, relating psychological distress to functionality. These authors reported that psychological distress could even predict survival and functional status 5 years after diagnosis.

We should recognize potential limitations to this study. First, the severity of psychological distress was not evaluated over time, so the temporal relationship between change in these problems, quality of life and symptom burden is unknown. However, our study design has based on previous studies where psychological distress was only evaluated once $[32,60]$. Second, the lack of a structured psychiatric clinical interview to assess depression and anxiety is also one of the limitations. Nevertheless, previous studies have used the HADS to evaluate the presence of psychological distress $[11,63]$.

Our findings demonstrate that psychological distress is an important consideration in the care of patients with lung cancer and that a brief screening of these problems prior to surgery can predict the evolution of symptoms and health status in the long term. A better understanding of the impact of psychological distress on cancer survivors could raise awareness, promote the development of better treatment strategies and improve the quality of life of these patients. So, future studies developing interventions that approach these disorders may be useful to improve the recovery and prognosis of these patients.

Therefore, the clinical impact of our results is evident. Detecting patients with psychological distress prior to surgery should be included in the usual clinical practice, due to its relevance. Clinicians, psychologists or nurses, among others, should know prognosis factors that could affect the lung cancer population.

\section{Conclusion}

Psychological distress is an important factor to take into account in lung cancer survivors. Patients with psychological distress prior to surgery present a greater symptom burden, with more dyspnoea, cough, fatigue and pain. With regard to health status, LC survivors with psychological distress before surgery presented a poorer self-perceived health status and lower functionality and sleep quality, than patients without distress 1 year after the lung resection.

Author contribution Marta Linares-Moya-conceptualization, methodology, supervision.

Janet Rodríguez-Torres-methodology, data curation, writing (original draft).

Alejandro Heredia-Ciuró-supervision, methodology.

María Granados-Santiago-data curation, visualization.

Laura López-López-methodology, data curation.

Florencio Quero-Valenzuela—data curation, supervision.

Marie C Valenza-conceptualization, methodology, formal analysis. 
Funding Funding for open access charge: Universidad de Granada/ CBUA. This work was supported by the Spanish Ministry of Education [grant numbers, FPU:16/01531 and FPU:17/00408] and the "Ilustre Colegio Profesional de Fisioterapeutas de Andalucía", through a project (05158/18P/MA).

Data availability Not applicable.

Code availability Not applicable.

\section{Declarations}

Ethics approval The study protocol was reviewed and approved by the University of Granada Ethics Committee (Granada, Spain). This study was performed in accordance with the Declaration of Helsinki (General Assembly of the World Medical Association, 2014).

Consent to participate All participants signed the informed consent previous to the inclusion in the study.

Consent for publication All authors give their consent for publication.

Conflict of interest The authors declare no competing interests.

Open Access This article is licensed under a Creative Commons Attribution 4.0 International License, which permits use, sharing, adaptation, distribution and reproduction in any medium or format, as long as you give appropriate credit to the original author(s) and the source, provide a link to the Creative Commons licence, and indicate if changes were made. The images or other third party material in this article are included in the article's Creative Commons licence, unless indicated otherwise in a credit line to the material. If material is not included in the article's Creative Commons licence and your intended use is not permitted by statutory regulation or exceeds the permitted use, you will need to obtain permission directly from the copyright holder. To view a copy of this licence, visit http://creativecommons.org/licenses/by/4.0/.

\section{References}

1. Siegel R, Naishadham D, Jemal A (2012) Cancer statistics. CA Cancer J Clin 62(1):10-29

2. Siegel R, Ma J, Zou Z, Jemal A (2014) Cancer statistics. CA Cancer J Clin 64:9-29

3. Kamoto T, Maruyama R, Shoji F, Asoh H, Ikeda J, Miyamoto T et al (2005) Long-term survivors in stage IV non-small cell lung cancer. Lung Cancer 47:85-91

4. Brock MV, Hooker CM, Syphard JE, Westra W, Xu L, Alberg AJ et al (2005) Surgical resection of limited disease small cell lung cancer in the new era of platinum chemotherapy: its time has come. J Thorac Cardiovasc Surg 129:64-72

5. Timmerman JG (2019) Cancer rehabilitation at home: the potential of telehealthcare to support functional recovery of lung cancer survivors. University of Twente, Enschede

6. Rowland JH, Aziz N, Tesauro G, Feuer EJ (2001) The changing face of cancer survivorship. Semin Oncol Nurs 17:236-240

7. Baker F, Denniston M, Smith T, West MM (2005) Adult cancer survivors: how are they faring? CA Cancer J Clin 104:2565-2576

8. Lowery AE, Krebs P, Coups EJ et al (2014) Impact of symptom burden in post-surgical non-small cell lung cancer survivors. Support Care Cancer 22:173-180
9. Yang P, Cheville AL, Wampfler JA et al (2012) Quality of life and symptom burden among long-term lung cancer survivors. J Thorac Oncol 7:64-70

10. Fagundes CP, Shi Q, Vaporciyan AA et al (2015) Symptom recovery after thoracic surgery: measuring patient-reported outcomes with the MD Anderson symptom inventory. J Thorac Cardiovasc Surg 150:613-619

11. Rodríguez J, Cabrera I, López L, Torres I, Granados M, Valenza MC (2019) Psychological distress at hospital admission is related to symptoms severity and health status in malignant pleural effusion patients. Eur J Cancer Care 29:e13212

12. Tishelman C, Lovgren M, Broberger E, Hamberg K, Sprangers MA (2010) Are the most distressing concerns of patients with inoperable lung cancer adequately assessed? A mixed-methods analysis. J Clin Oncol 28:1942-1949

13. Akin S, Can G, Aydiner A, Ozdilli K, Durna Z (2010) Quality of life, symptom experience and distress of lung cancer patients undergoing chemotherapy. Eur J Oncol Nurs 14:400-409

14. Holland JC, Andersen B, Breitbart WS, Buchmann LO, Compas B, Deshields TL et al (2013) Distress management. J Natl Compr Canc Netw 11:90e209

15. Agarwal J, Powers K, Pappas L, Buchmann L, Anderson L, Gauchay L et al (2013) Correlates of elevated distress thermometer scores in breast cancer patients. Support Care Cancer 21:2125-2136

16. Shim EJ, Shin YW, Jeon HJ, Hahm BJ (2008) Distress and its correlates in Korean cancer patients: pilot use of the distress thermometer and the problem list. Psychooncology 17:548-555

17. Grassi L, Johansen C, Annunziata MA, Capovilla CA, Gritti P et al (2013) Italian Society of Psycho-Oncology Distress Thermometer Study Group. Cancer 119:1714-1721

18. Vodermaier A, Linden W, MacKenzie R, Greig D, Marshall C (2011) Disease stage predicts post-diagnosis anxiety and depression only in some types of cancer. Br J Cancer 105:1814-1817

19. Randall JM, Voth R, Burnett E, Bazhenoval L, Bardwell WA (2013) Clinic-based depression screening in lung cancer patients using the PHQ-2 and PHQ-9 depression questionnaires: a pilot study. Support Care Cancer 21:503-507

20. Vodermaier A, Lucas S, Linden W, Olson R (2017) Anxiety after diagnosis predicts lung cancer-specific and overall survival in patients with stage III non-small cell lung cancer: a population-based Cohort study. J Pain Symptom Manag 53:1057-1065

21. Carlson LE, Angen M, Cullum J, Goodey E, KoopmansJ LL, Bultz BD (2004) High levels of untreated distress and fatigue in cancer patients. Br J Cancer 90:2297-2304

22. Chambers SK, Dunn J, Occhipinti S, Hughes S, Baade P, Sinclair $S$ et al (2012) A systematic review of the impact of stigma and nihilism on lung cancer outcomes. BMC Cancer 12:184

23. Morrison E, Novotny PJ, Sloan JA, Yang P, Patten CA, Ruddy $\mathrm{KJ}$ et al (2017) Emotional problems, quality of life, and symptom burden in patients with lung cancer. Clin Lung Cancer $18: 497-503$

24. Mou Q, Yu C, Li J (2016) Investigation and analysis for impact factors of distress in patients with first diagnosed lung cancer. Health Science 48:507-514

25. Fox SW, Lyon DE (2006) Symptom clusters and quality of life in survivors of lung cancer. Oncol Nurs Forum 33(5):931-6

26. Watson D, Pennebake JW (1989) Health complaints, stress, and distress: exploring the central role of negative affectivity. Psychol Rev 96:234-254

27. Costa PT, McCrae RR (1987) Neuroticism, somatic complaints, and disease: is the bark worse than the bite? J Pers 55:299-316

28. Barsky AJ, Goodson JD, Lane RS et al (1988) The amplification of somatic symptoms. Psychosom Med 50(1988):510-519

29. Bultz BD, Carlson LE (2006) Emotional distress: the sixth vital sign—future directions in cancer care. Psychooncology 15:93-95 
30. Pozo CLP, Morgan MAA, Gray JE (2014) Survivorship issues for patients with lung cancer. Cancer Control J Moffitt Cancer Cent 21:40-50

31. Charlson ME, Pompei P, Ales KL, MacKenzie CR (1987) A new method of classifying prognostic comorbidity in longitudinal studies: development and validation. J Chronic Dis 40:373-383

32. Park S, Kang CH, Hwang Y, Seong YW, Lee HJ, Park IK et al (2015) Risk factors for postoperative anxiety and depression after surgical treatment for lung cancer. Eur J Cardiothorac Surg 49:e16-e21

33. Snaith RP (2003) The hospital anxiety and depression scale. Health Qual Life Outcomes 1:29

34. Üstün TB, Kostanjsek N, Chatterji S, Rehm J (2010) Measuring health and disability: manual for WHO disability assessment schedule WHODAS 2.0. World Health Organization

35. Federici S, Bracalenti M, Meloni F, Luciano JV (2017) World Health Organization disability assessment schedule 2.0: an international systematic review. Disabil Rehabil 39:2347-2380

36. Haylett R, Gustafson O (2018) A feasibility study to assess preadmission status and six month outcomes of major trauma patients admitted to an intensive care unit, using the WHO DAS 2.0. J Crit Care 48:140-144

37. Badia X, Roset M, Montserrat S, Herdman M, Segura A (1999) The Spanish version of EuroQol: a description and its applications. European Quality of Life scale. Med Clin 112:79-85

38. Buysse D, Reynolds C, Monk T, Berman S, Kupfer D (1989) The Pittsburgh sleep quality index: a new instrument for psychiatric practice and research. Psychiatry Res 28:193-213

39. Mollayeva T, Thurairajah P, Burton K, Mollayeva S, Shapiro C, Colantonio A (2016) The Pittsburgh sleep quality index as a screening tool for sleep dysfunction in clinical and non-clinical samples: a systematic review and meta-analysis. Sleep Med Rev 25:52-73

40. Banzett RB, O'Donnell CR, Guilfoyle TE, Parshall MB, Schwartzstein RM, Meek PM et al (2015) Multidimensional Dyspnoea Profile: an instrument for clinical and laboratory research. Eur Respir J 45:1681-1691

41. Gilet H, Pignier C, Aguilaniu B, Devillier P, Didier A, Perez T et al (2015) PRM169 - Psychometric Validation of the Multidimensional Dyspnea Profile (Mdp) Questionnaire. Value Health 18:A712

42. Kumar SP (2011) Utilization of brief pain inventory as an assessment tool for pain in patients with cancer: a focused review. Indian J Palliat Care 17:108-115

43. Tittle MB, McMillan SC, Hagan S (2003) Validating the brief pain inventory for use with surgical patients with cancer. Oncol Nurs Forum 30:325-332

44. Krupp LB, LaRocca NG, Muir-Nash J, Steinberg AD (1989) The Fatigue Severity Scale: application to patients with multiple sclerosis and systemic lupus erythematosus. Arch Neurol 46:1121-1123

45. Birring SS, Prudon B, Carr AJ, Singh SJ, Morgan MD, Pavord ID (2003) Development of a symptom specific health status measure for patients with chronic cough: Leicester Cough Questionnaire (LCQ). Thorax 58:339-343

46. Munoz G, Buxó M, de Gracia J, Olveira C, Martinez-Garcia MA, Giron R et al (2016) Validation of a Spanish version of the Leicester Cough Questionnaire in non-cystic fibrosis bronchiectasis. Chron Respir Dis 13(2):128-136

47. Blichfeldt-Eckhardt MR, Andersen C, Ørding H, Licht PB, Toft P (2017) Shoulder pain after thoracic surgery: type and time course, a prospective cohort study. J Cardiothorac Vasc Anesth $31: 147-151$

48. Blichfeldt-Eckhardt MR, Laursen CB, Berg H et al (2016) A randomised, controlled, double-blind trial of ultrasound-guided phrenic nerve block to prevent shoulder pain after thoracic surgery. Anaesthesia 71:1441-1448

49. Rodríguez J, Lucena MDM, Cabrera I, López L, Torres I, Valenza MC (2019) musculoskeletal signs associated with shoulder pain in patients undergoing video-assisted thoracoscopic surgery. Pain Med 20:1997-2003

50. Hopwood P, Stephens RJ (2000) Depression in patients with lung cancer: prevalence and risk factors derived from quality-of-life data. J Clin Oncol 18:893-903

51. Lin S, Chen Y, Yang L, Zhou J (2013) Pain, fatigue, disturbed sleep and distress comprised a symptom cluster that related to quality of life and functional status of lung cancer surgery patients. J Clin Nurs 22:1281-1290

52. Locke DE, Decker PA, Sloan JA et al (2007) Validation of singleitem linear analog scale assessment of quality of life in neurooncology patients. J Pain Symptom Manag 34:628-638

53. Shi Q, Smith TG, Michonski JD, Stein KD, Kaw C, Cleeland CS (2011) Symptom burden in cancer survivors 1 year after diagnosis: a report from the American Cancer Society's Studies of Cancer Survivors. Cancer 117:2779-2790

54. Laird BJ, Scott AC, Colvin LA et al (2011) Pain, depression, and fatigue as a symptom cluster in advanced cancer. J Pain Symptom Manag 42:1-11

55. Fitzgerald P, Lo C, Li M, Gagliese L, Zimmermann C, Rodin $G$ (2015) The relationship between depression and physical symptom burden in advanced cancer. BMJ Support Palliat Care 5:381-388

56. Tishelman C, Petersson LM, Degner LF, Sprangers MAG (2007) Symptom prevalence, intensity, and distress in patients with inoperable lung cancer in relation to time of death. J Clin Oncol 25:5381-5389

57. Arrieta O, Angulo LP, Núñez C et al (2013) Association of depression and anxiety on quality of life, treatment adherence, and prognosis in patients with advanced non-small cell lung cancer. Ann Surg Oncol 20:1941-1948

58. Gonzalez M, Bilbao A, Baré M et al (2016) Association of social support, functional status, and psychological variables with changes in health-related quality of life outcomes in patients with colorectal cancer. Psychooncology 25:891-897

59. Miaskowski C, Paul SM, Cooper BA et al (2011) Predictors of the trajectories of self-reported sleep disturbance in men with prostate cancer during and following radiation therapy. Sleep 34:171-179

60. Nishiura M, Tamura A, Nagai H, Matsushima E (2015) Assessment of sleep disturbance in lung cancer patients: relationship between sleep disturbance and pain, fatigue, quality of life, and psychological distress. Palliat Support Care 13:575-581

61. Chang WP, Lin CC (2017) Relationships of salivary cortisol and melatonin rhythms to sleep quality, emotion, and fatigue levels in patients with newly diagnosed lung cancer. Eur J Oncol Nurs 29:79-84

62. Cheville AL, Novotny PJ, Sloan JA, Basford JR, Wampfler JA, Garces YI et al (2011) Fatigue, dyspnea, and cough comprise a persistent symptom cluster up to five years after diagnosis with lung cancer. J Pain Symptom Manag 42:202-212

63. Paine NJ, Bacon SL, Bourbeau J, Tan WC, Lavoie KL, Aaron SD et al (2019) Psychological distress is related to poor health behaviours in COPD and non-COPD patients: evidence from the CanCOLD study. Respir Med 146:1-9

Publisher's note Springer Nature remains neutral with regard to jurisdictional claims in published maps and institutional affiliations. 